The following abbreviations are used for items frequently cited in footnotes and the bibliography. I cite critical editions and translations in my footnotes by giving the name of editor(s) or translator and page number of the texts, sometimes with series name and line number (indicated by commas) added. Full citations are given in the bibliography. All translations are my own except where indicated.

$\begin{array}{ll}\text { AASS } & \text { Acta Sanctorum } \\ \text { AB } & \text { Analecta Bollandiana } \\ \text { ACO } & \text { Acta Conciliorum Oecumenicorum. Ed. E. Schwartz } \\ \text { ACW } & \text { Ancient Christian Writers (translation series) } \\ \text { ANF } & \text { Ante-Nicene Fathers (translation series) } \\ B Z & \text { Byzantinische Zeitschrift } \\ \text { CCSL } & \text { Corpus Christianorum, Series Latina } \\ \text { CIL } & \text { Corpus Inscriptionum Latinarum } \\ C J & \text { Codex Justinianus. Ed. P. Krüger } \\ \text { CS } & \text { Cistercian Studies (translation series) } \\ \text { CSCO } & \text { Corpus Scriptorum Christianorum Orientalium } \\ \text { CSEL } & \text { Corpus Scriptorum Ecclesiasticorum Latinorum } \\ C T h & \text { Codex Theodosianus. Ed. Th. Mommsen and P. M. Meyer } \\ \text { DACL } & \text { Dictionnaire d'archéologie chrétienne et de liturgie } \\ D H G E & \text { Dictionnaire d'histoire et de géographie ecclésiastique } \\ D S p & \text { Dictionnaire de spiritualité } \\ \text { Ep. } & \text { Epistula, Epistulae } \\ \text { GCS } & \text { Die griechischen christlichen Schriftsteller der ersten } \\ & \text { Jahrhunderte }\end{array}$


Hefele-Leclerq C. J. Hefele and H. Leclerq, Histoire des conciles d'après les documents originaux. Vols. 1.1-2.2.

$H E$ Historia ecclesiastica

$H L$ Palladius, Historia Lausiaca

$H M$ Historia monachorum in Aegypto

$H R$ Theodoret of Cyrrhus, Historia religiosa

$J b A C$ $J E C S$ Jahrbuch für Antike und Christentum JEH Journal of Early Christian Studies Journal of Ecclesiastical History

$J R S$

JThS Journal of Roman Studies

Lampe Journal of Theological Studies

LCL

$L H$

NPNF

OCA

$O C P$

PapETSE

PG

PL G. W. H. Lampe, A Patristic Greek Dictionary

Loeb Classical Library

Nestorius, Liber Heraclidis

Nicene and Post-Nicene Fathers (translation series)

Orientalia Christiana Analecta

Orientalia Christiana Periodica

Papers of the Estonian Theological Society in Exile Patrologia Graeca

PLRE 1

\section{Patrologia Latina}

The Prosopography of the Later Roman Empire. Vol. 1 (A.D. 26o-395). Ed. A. H. M. Jones, J. R. Martindale, and J. Morris.

PLRE 2

PLS

PO

The Prosopography of the Later Roman Empire. Vol. 2 (A.D. 395-527). Ed. J. R. Martindale.

PS

Patrologiae Latinae Supplementum

Patrologia Orientalis

PTS

Patrologia Syriaca

Patristische Texte und Studien

$R E B$

Revue des études byzantines

RHE

Revue d'histoire ecclésiastique

RHR

Revue de l'histoire des religions

RevSR

Revue de science religieuse

$R O C$

$\mathrm{SC}$

Revue de l'Orient chrétien

$\mathrm{SH}$

$S M$

$S P$

TS

Sources chrétiennes

Subsidia Hagiographica

Studia Monastica

Studia Patristica

TU

Text and Studies

$V C$

$Z K G$

Texte und Untersuchungen

Vigiliae Christianae

ZPE

Zeitschrift für Kirchengeschichte

Zeitschrift für Papyrologie und Epigraphik 


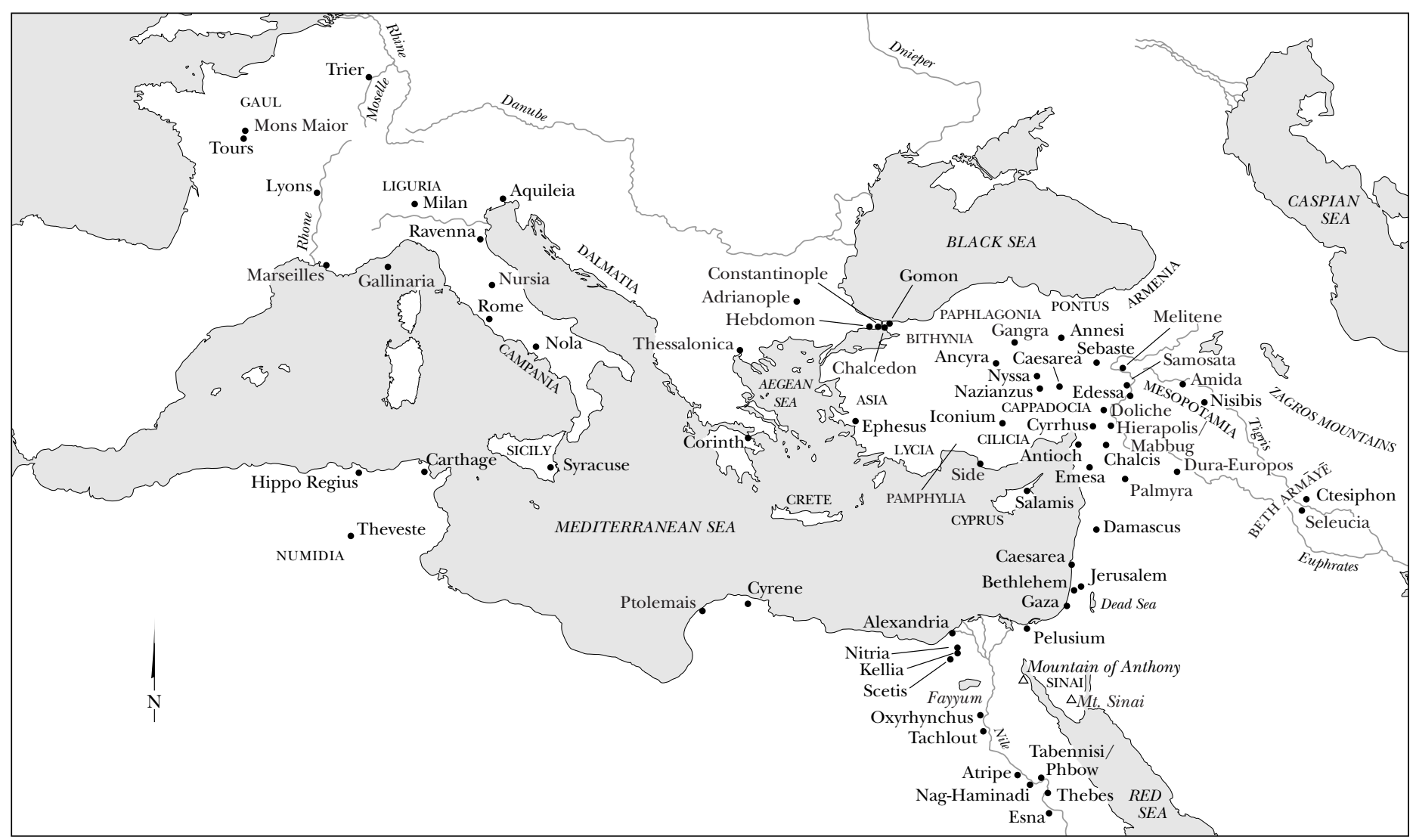


This page intentionally left blank 